\title{
Mortality from COVID-19 in patients with lung cancer
}

\author{
Amit A. Kulkarni ${ }^{1}$, Grace Wilson ${ }^{2}$, Naomi Fujioka ${ }^{1}$, Manish R. Patel ${ }^{1}$ \\ 1Division of Hematology, Oncology and Transplantation, Department of Medicine, University of Minnesota, Minneapolis, MN \\ 55455, USA. \\ ${ }^{2}$ University of Minnesota Medical School, Minneapolis, MN 55455, USA.
}

Correspondence to: Assist. Prof. Amit A. Kulkarni M.D., Division of Hematology, Oncology, Transplant, University of Minnesota, 420 Delaware St SE, Minneapolis, MN 55455, USA. E-mail: kulkarni@umn.edu

\begin{abstract}
How to cite this article: Kulkarni AA, Wilson G, Fujioka N, Patel MR. Mortality from COVID-19 in patients with lung cancer. J Cancer Metastasis Treat 2021;7:31. https://dx.doi.org/10.20517/2394-4722.2021.36
\end{abstract}

Received: 5 Feb 2021 First Decision: 13 Apr 2021 Revised: 6 May 2021 Accepted: 19 May 2021 Published: 11 Jun 2021

Academic Editor: Lucio Miele Copy Editor: Yue-Yue Zhang Production Editor: Yue-Yue Zhang

\begin{abstract}
The World Health Organization declared coronavirus infectious disease-2019 (COVID-19) linked to the severe acute respiratory syndrome (SARS-CoV-2), a global pandemic in March 2020. The pandemic outbreak has led to the most unprecedented and catastrophic loss of human life in the recent history. As of January 2021, there were more than 100 million cases of COVID-19 and more than two million deaths worldwide. Compared to the general population, patients with cancer are at a higher risk of poor outcomes from COVID-19. In large cohort studies, mortality from COVID-19 in patients with cancer can be as high as 40\%. In addition to clinical variables (older age, male sex, and co-morbidities) that are associated with mortality in general population, cancer patients are uniquely vulnerable to severe COVID-19 due to immunosuppression from cancer and its therapy, and disruption of routine clinical care. Among patients with cancer, the lung cancer population is at a higher risk of poor outcomes and mortality from COVID-19 for several reasons. For instance, lung is the main target organ in COVID-19 that can lead to respiratory failure, patients with lung cancer have baseline poor lung function from chronic obstructive pulmonary disorder and smoking. In addition, some of the lung cancer treatment side-effects like pneumonitis, may obscure the diagnosis of COVID-19. In this article, we systematically review the most impactful cohort studies published to date in patients with cancer and COVID-19. We describe the rates of mortality in patients with cancer and COVID-19 with a special focus on the lung cancer population. We also summarize the factors associated with poor outcomes and mortality in patients with lung cancer and COVID-19.
\end{abstract}

Keywords: Coronavirus, COVID-19, lung cancer, mortality 


\section{INTRODUCTION}

Lung cancer is the leading cause of cancer-related death worldwide with approximately 136,000 deaths estimated in 2020 in the Unites States alone ${ }^{[1]}$. Coronavirus disease-2019 (COVID-19) is a respiratory tract infection caused by the novel coronavirus, severe acute respiratory syndrome coronavirus-2 (SARS-CoV2) that has quickly escalated into a global pandemic after initial outbreak in Wuhan province, China in December 2019. The United States was the epicenter of the outbreak, with more than 25 million people testing positive for COVID-19 and more than 400,000 deaths attributed to COVID-19 as of January $2021^{[2]}$. COVID-19 severity can range widely from an asymptomatic or mild flu-like illness to respiratory failure and severe acute respiratory distress syndrome. Large cohort studies have shown that clinical factors consistently associated with increased risk of death from COVID-19 include older age, male sex, and comorbidities such as hypertension, diabetes, obesity, and cancer ${ }^{[3,4]}$. Biomarkers associated with poor outcomes include lymphocytopenia, elevated D-Dimer, elevated C-reactive protein, elevated cardiac troponin and elevated interleukin-6 $6^{[5,6]}$. Patients with cancer are highly vulnerable to COVID-19 due to their immunocompromised state, frequent contact with the health care system, advanced age and comorbidities, putting them in the highest-risk category for COVID-19-related morbidity and mortality. During the early phase of the pandemic, there were limited data on the impact of COVID-19 in patients with cancer. Recent studies have consistently shown increased rates of hospitalization, higher COVID-19-related mortality and higher all-cause mortality in patients with cancer ${ }^{[7-15]}$. In published studies, the mortality of cancer patients with COVID-19 can range from $16 \%$ to as high as $40 \%^{[7-15]}$. While patients with cancer clearly have worse outcomes from COVID-19, data on patients with lung cancer and COVID-19 are limited. Available data suggest that patients with lung cancer may be at a higher risk of severe COVID-19 infection due to compromised lung function from smoking and chronic-obstructive pulmonary disorder (COPD $)^{[1,16]}$. In addition, patients with lung cancer often have symptoms that overlap with COVID-19, potentially causing a delay in diagnosis. Furthermore, radiographic findings of COVID-19 may be difficult to distinguish from pneumonitis caused by immunotherapy, radiation, or targeted therapies for lung cancer. In this article, we provide a comprehensive review of the literature related to COVID-19 and cancer and report data specific for COVID-19 mortality in patients with lung cancer.

\section{EVIDENCE FROM LARGE COVID-19 AND CANCER COHORT STUDIES - FOCUSING ON LUNG CANCER}

Early reports from China showed a higher burden of COVID-19 in patients with cancer ${ }^{[17]}$ but were limited by sample size, short follow-up time and lack of information on cancer status and cancer-specific treatment. Recently, several large, multi-institutional cohort studies dedicated to cancer patients with COVID-19 have provided more insights on the risk factors associated with a worse outcome [Table 1]. One of the first large cohort studies reported was from Wuhan, China which compared 105 patients with COVID-19 and cancer to 536 age-matched controls without any cancer ${ }^{[9]}$. In the study, patients with cancer had higher death rates [Odds ratio $(\mathrm{OR})=2.34,95 \%$ confidence interval $(\mathrm{CI}): 1.15-4.77, P=0.03$ ], higher rates of intensive care unit (ICU) admission ( $\mathrm{OR}=2.84,95 \% \mathrm{CI}: 1.59-5.08, P<0.01)$, and higher chances of requiring invasive mechanical ventilation. The mortality was $11.4 \%$ in patients with cancer compared to $4.9 \%$ in those without cancer. In this study, lung cancer was the most prevalent cancer type (20.95\%), followed by gastrointestinal cancer $(12.38 \%)$ and breast cancer (10.48\%). Patients with lung cancer had the second-highest risk for adverse outcomes; the mortality was $18.1 \%$, the ICU admission rate was $27.2 \%$, and $18.1 \%$ required mechanical ventilation. In another study across 9 hospitals in Hubei province, China, clinical outcomes of 205 patients with cancer and COVID-19 were reported ${ }^{[13]}$. The majority of patients had solid tumor malignancies (89\%); breast cancer (20\%), colorectal (14\%) and lung cancer (12\%) were the most common malignancies. The overall mortality rate was $20 \%$ across all cancer types. However, those with lung cancer had the highest mortality of $25 \%$. Multivariable regression analysis showed that receiving cytotoxic 
Table 1. Key studies highlighting the mortality rates in all cancers and lung cancers

\begin{tabular}{|c|c|c|c|c|}
\hline Study & Study population & Study size $(N)$ & $\begin{array}{l}\text { Mortality in patients with } \\
\text { any cancer }\end{array}$ & $\begin{array}{l}\text { Mortality in patients with } \\
\text { lung cancer }\end{array}$ \\
\hline Dai et al. ${ }^{[9]}$ & Chinese & $\begin{array}{l}105 \text { (All cancers) } \\
22 \text { (Lung cancer) }\end{array}$ & $11.4 \%$ & $18.1 \%$ \\
\hline Yang et al. ${ }^{[13]}$ & Chinese & $\begin{array}{l}205 \text { (All cancers) } \\
25 \text { (Lung cancer) }\end{array}$ & $20 \%$ & $25 \%$ \\
\hline Mehta et al. ${ }^{[10]}$ & United States & $\begin{array}{l}218 \text { (All cancers) } \\
11 \text { (Lung cancer) }\end{array}$ & $28 \%$ & $55 \%$ \\
\hline Luo et al. ${ }^{[16]}$ & United States & 101 (Lung cancer) & NA & $25 \%$ \\
\hline Lee et al. ${ }^{[8]}$ & United Kingdom & $\begin{array}{l}800 \text { (All cancers) } \\
90 \text { (Lung cancer) }\end{array}$ & $28 \%$ & $14 \%$ \\
\hline Kuderer et al. ${ }^{[7]}$ & United States and Canada & $\begin{array}{l}928 \text { (All cancers) } \\
92 \text { (Lung cancer) }\end{array}$ & $13 \%$ & $26 \%$ \\
\hline Garassino et al. ${ }^{[1,20]}$ & European & 400 (Lung cancer) & NA & $35 \%$ \\
\hline
\end{tabular}

NA: Not applicable.

chemotherapy (but not targeted therapy) within 4 weeks before symptom onset (OR $=3.51,95 \% \mathrm{CI}$ : 1.16 $10.59, P=0.026)$ and male sex $(\mathrm{OR}=3.86,95 \% \mathrm{CI}: 1.57-9.50, P=0.0033)$ were associated with increased mortality.

In the United States, one of the first studies to report experience with cancer and COVID-19 was the singleinstitution study from the Montefiore Health system in New York, NY, the epicenter of infection in the early stages of the pandemic. In this study, 218 patients with cancer and COVID-19 were included ${ }^{[10]}$. The mortality was $28 \%$ across all cancers. Amongst patients with solid tumor malignancies, the eleven patients with lung cancer had the highest mortality (55\%). In the multivariate model, older age (age $<65, \mathrm{OR}=0.23$, 95\%CI: 0.07-0.6), higher composite comorbidity score (composite score defined as the sum of indicators for diabetes mellitus, hypertension, chronic lung disease, chronic kidney disease, coronary artery disease, and congestive heart failure capped at a maximum of 3) ( $\mathrm{OR}=1.52,95 \% \mathrm{CI}: 1.02-2.33)$, ICU admission ( $\mathrm{OR}=$ 4.83, 95\%CI: 1.46-17.15), and elevated inflammatory markers (D-dimer, lactate, and lactate dehydrogenase) were significantly associated with mortality. Advanced metastatic disease and active disease showed a trend for increased mortality but did not meet statistical significance. Similarly, active chemotherapy or radiation treatment was not associated with increased fatality. The number of patients on immunotherapy was negligible.

Another single-institution study from New York showed that patients with lung cancer $(N=102)$ and COVID-19 had high rates of hospitalization $(65 \%)$ and death $(25 \%)^{[16]}$. Similar to other studies, advancing age $(\mathrm{OR}=2.01,95 \% \mathrm{CI}: 1.34-3.19)$, smoking history [OR $=2.9,95 \% \mathrm{CI}: 1.07-9.44$, comparing the median (23.5 pack-years) to never-smoker], COPD (OR $=3.87,95 \% \mathrm{CI}: 1.35-9.68)$, and hypertension $(\mathrm{OR}=2.68$, 95\%CI: 1.14-6.14) were associated with increased risk of severe COVID-19. Active/metastatic lung cancer, history of prior thoracic radiation or thoracic surgery did not appear to impact the severity of COVID-19 infection. Another smaller study in patients with lung cancer $(N=41)$ who received immunotherapy showed numerical increase in COVID-19 severity (univariate OR, 1.18-1.81 for severity outcomes); however, when adjusted for smoking history, immunotherapy exposure did not significantly impact risk of hospitalization, ICU admission, or death ${ }^{[18]}$.

COVID-19 and Cancer Consortium (CCC-19) from the US, and the United Kingdom Coronavirus Cancer Monitoring Project (UKCCMP) are the two largest pan-cancer cohorts to study the impact of cancer on COVID-19 infection. The UKCCMP study analyzed 800 patients with a diagnosis of cancer and 
symptomatic COVID-19 ${ }^{[8]}$. The mortality was $28 \%$ amongst these patients. Patients with lung cancer had mortality of $14 \%$, whereas mortality of patients with gastrointestinal cancers was $19 \%$. Mortality was significantly associated with advanced age $(\mathrm{OR}=9.42,95 \% \mathrm{CI}$ : 6.56-10.02, $P<0.0001)$, male sex $(\mathrm{OR}=1.67$, 95\%CI: 1.19-2.34, $P=0.003$ ), and comorbidities such as hypertension ( $\mathrm{OR}=1.95,95 \% \mathrm{CI}: 1.36-2.80, P<$ $0.001)$ and cardiovascular disease $(\mathrm{OR}=2.32,95 \% \mathrm{CI}: 1.47-3.64)$. When compared to patients who did not receive recent chemotherapy, patients who received cytotoxic chemotherapy within 4 weeks of a diagnosis of COVID-19 $(N=281,35 \%)$ did not appear to have a greater COVID-19 related mortality (OR = 1.18, 95\%CI: $0.81-1.72, P=0.380$ ). Similarly, there was no significant effect on mortality associated with other classes of cancer therapy such as immunotherapy, hormonal therapy, targeted therapy, or radiotherapy use within 4 weeks of COVID-19 diagnosis. However, the number of patients on these therapies was low $(<10 \%$ for each therapy). Further details specifically on patients with lung cancer were not published.

Initial results from CCC-19 included 928 patients with cancer and lab-confirmed COVID-19 accrued through April 2020. Breast (20\%) and prostate (16\%) cancers were most prevalent, and thoracic malignancies comprised $10 \%$ of the cohort ${ }^{[7]}$. By the time of data analysis, 242 patients $(26 \%)$ had met the composite outcome of death, severe illness requiring hospitalization, and/or mechanical ventilation. Thirtyday mortality rate was $13 \%(N=121)$. Multivariable analysis demonstrated that independent factors associated with increased 30-day mortality were increased age (per 10 years, OR = 1.84, 95\%CI: 1.53-2.21), male sex $(\mathrm{OR}=1.63,95 \% \mathrm{CI}: 1.07-2.48)$, smoking status (former smoker $v s$. never smoked: $\mathrm{OR}=1.60$, 95\%CI: 1.03-2.47), the number of comorbidities (two vs. none: $\mathrm{OR}=4.50,95 \% \mathrm{CI}$ : $1.33-15.28$ ), Eastern Cooperative Oncology Group (ECOG) performance status of 2 or higher (status of 2 vs. 0 or 1: OR = 3.89, 95\%CI: 2.11-7.18), active cancer (progressing vs. remission: $\mathrm{OR}=5.20,95 \% \mathrm{CI}: 2.77-9.77$ ), and receipt of azithromycin plus hydroxychloroquine ( $v s$. treatment with neither: $\mathrm{OR}=2.93,95 \% \mathrm{CI}$ : 1.79-4.79). Subgroup analysis showed that neither cancer type nor its treatment was associated with 30-day all-cause mortality; however, due to limited statistical power, extensive analysis (e.g., comparing patients with thoracic malignancies to others) was not feasible. The most updated analysis included 2749 patients with cancer and COVID-19 ${ }^{[19]}$. Twenty-nine percent $(N=810)$ of the patients had met the composite outcome of death, severe illness requiring hospitalization, and/or mechanical ventilation. Overall, 30-day all-cause mortality for the CCC-19 cohort increased to $16 \%(N=433)$ and about $60 \%(N=1637)$ of the patients required hospitalization. These increases are presumably due to longer median follow-up, as opposed to a general worsening of COVID-19. Factors associated with an increased 30-day mortality were similar. However, none of the cancer therapies (cytotoxic chemotherapy, immunotherapy, targeted therapy, endocrine therapies, and radiation) were independently associated with an increased risk of 30-day all-cause mortality. In this cohort, patients with lung cancer had one of the highest mortality rates of $26 \%$ ( $N=61$ of 237), while thyroid and breast cancer had the lowest mortality rate among all malignancies ( $3 \%$ and $8 \%$, respectively).

Thus far, the largest dataset dedicated to lung cancer and COVID-19 is the TERAVOLT (Thoracic Cancers International COVID-19 collaboration) global registry, which has provided a greater understanding of the patient- and cancer-specific risk factors in patients with lung cancer suffering from COVID-19 infection ${ }^{[11]}$. The TERAVOLT study initially reported 200 patients with thoracic cancers and COVID-19 across 8 countries, the vast majority had non-small cell lung cancer $[N=151(76 \%), 147(74 \%)]$ had stage 4 disease and $147(74 \%)$ were on active systemic cancer treatment. Similar to CCC-19, the hospitalization rates were striking $(76 \%)$, and overall mortality was as high as $33 \%$. On multivariable analysis, only smoking was associated with increased risk of mortality ( $\mathrm{OR}=3.18,95 \% \mathrm{CI}$ : 1.11-9.06). More importantly, any systemic therapy, including targeted therapies $(28 / 147,19 \%)$, chemotherapy $(48 / 147,33 \%)$, and immunotherapy (23\%) or combination chemo-immunotherapy (14\%), did not affect survival in patients with COVID-19. An updated analysis of 400 patients in TERAVOLT was presented at the American society of clinical oncology 
(ASCO) Annual Meeting 2020 ${ }^{[20]}$. Hospitalization rates (78\%) and overall mortality were similar (35\%) to the previously published data. However, in the updated analysis, patients with age $>65$ (OR $=1.70,95 \%$ CI: 1.092.63, $P=0.018)$, presence of comorbidities, ECOG PS $\geq 1$ ( $\mathrm{OR}=2.14,95 \% \mathrm{CI}: 1.11-4.11, P<0.001)$, use of steroids (equivalent of prednisone $>10 \mathrm{mg} /$ day) $(\mathrm{OR}=1.49,95 \% \mathrm{CI}: 1.00-2.23, P=0.052)$ and anticoagulation prior to COVID-19 diagnosis were associated with increased risk of death. As opposed to earlier analysis, prior administration of chemotherapy (alone or with immunotherapy) within 3 months of COVID-19 diagnosis ( $\mathrm{OR}=1.71,95 \% \mathrm{CI}: 1.12-2.63, P=0.025)$ was associated with increased risk of death. Whereas receipt of immunotherapy or targeted therapy did not increase risk for mortality. In a sub-group analysis, patients with rare thoracic malignancies (small cell lung cancer, mesothelioma) appeared to have mortality of $40 \%{ }^{[2]}$. Furthermore, TERAVOLT recently presented updated analysis from 1053 patients at the 2020 World Conference on Lung Cancer meeting ${ }^{[22]}$. The overall mortality was similar to that in the previous studies (33\%). On multivariate analysis, male sex, older age, worse performance status, and four or more metastatic sites were associated with increased risk of death. Race and ethnicity did not seem to affect the risk of death. Full results of this data are awaiting publication. Table 2 summarizes the factors associated with severe COVID-19 and or mortality across all the studies.

\section{CONCLUSIONS}

Metanalyses of independent studies have consistently shown high mortality in patients with cancer and COVID-19. For instance, in a metanalyses study of 2922 patients across 18 studies, the pooled 30-day mortality rate was $30 \%$ in hospitalized patients where as it was about $15 \%$ among patients who were treated either in hospital or outpatient setting ${ }^{[23]}$. In another metanalysis of 15 studies among 3019 patients, the mortality rate was $22.4 \%{ }^{[24]}$. In both studies a higher mortality was associated with older age and male gender. In comparison to other cancers, patients with lung cancer and COVID-19 particularly have a disproportionately higher mortality ranging from $11 \%$ to $40 \%$. Amongst all studies, clinical factors consistently associated with increased risk of severe COVID-19 or death in lung cancer patients include advancing age, and comorbidities such as hypertension or smoking history. In the largest studies to date in lung cancer population, use of cytotoxic chemotherapy (alone or in combination with immunotherapy) has shown increased risk for mortality ${ }^{[20]}$. In contrast, none of the other studies or metanalyse ${ }^{[25]}$ reported this association with the caveat that most of these studies were across all cancers. Reassuringly, use of immunotherapy or targeted therapy was not convincingly associated with increased mortality in any studies. While these data may be limited by short follow-up time, it suggests that providers should not withhold or delaying lung cancer treatment significantly due to the risk of COVID-19. The pandemic has resulted in substantial challenges to cancer care delivery leading to significant delays in screening and diagnosis, systemic therapy, and curative intent surgery. The long-term impact of this delay has yet to be determined. National and international societies like ASCO, National comprehensive cancer network and European society of medical oncology have issued guidelines for lung cancer care during the COVID-19 pandemic based on risk stratification, comorbidities, and stage of cancer ${ }^{[26-28]}$. While COVID-19 infection is potentially disproportionately life-threatening for patients with lung cancer, the risks in delaying cancer care can likewise result in devastating outcomes. As we evolve and adapt to emerging data, we encourage institutions to continue to approach the treatment of patients with lung cancer in an individualized, multidisciplinary approach. While highly effective vaccines are currently being rolled out, and bring hope to patients and providers alike, it is projected that several more months will pass before high-risk patients such as those with lung cancer will have access to the vaccine. Therefore, ongoing mitigation efforts like mask or face covering, physical distancing, and optimizing virtual care will continue to be fundamental in the fight against the COVID-19 pandemic and its devastating impact on patients with cancer. 
Table 2. Factors associated with severe COVID-19 and or mortality on multivariable regression analysis"

\begin{tabular}{|c|c|c|c|c|c|c|c|c|c|c|}
\hline \multirow{3}{*}{ Study } & \multirow{3}{*}{ Cancer type } & \multicolumn{9}{|c|}{ Factors associated with severe COVID-19 and or mortality } \\
\hline & & \multicolumn{4}{|c|}{ Comorbidities } & \multirow{2}{*}{$\begin{array}{l}\text { ECOG } \\
\text { status }\end{array}$} & \multirow[b]{2}{*}{ Cancer status } & \multirow{2}{*}{$\begin{array}{l}\text { Laboratory } \\
\text { variables }\end{array}$} & \multicolumn{2}{|c|}{ Treatment exposure } \\
\hline & & Age & $\begin{array}{l}\text { Male } \\
\text { gender }\end{array}$ & Smoking & Others & & & & For COVID & For cancer \\
\hline Yang et al. ${ }^{[13]}$ & $\begin{array}{l}\text { All cancers }(N= \\
105)\end{array}$ & NA & $\begin{array}{l}\text { OR }=3.86 \\
(1.57- \\
9.50), P= \\
0.0033)\end{array}$ & NA & NA & NA & NA & NA & NA & $\begin{array}{l}\text { Cytotoxic chemotherapy } \\
\text { (OR }=3.51,95 \% \mathrm{Cl}: 1.16- \\
10.59, P=0.026)\end{array}$ \\
\hline Mehta et al. ${ }^{[10]}$ & $\begin{array}{l}\text { All cancers }(N= \\
105)\end{array}$ & $\begin{array}{l}\text { Age }<65 \text { (OR } \\
=0.23 \\
95 \% \mathrm{Cl}: 0.07- \\
0.6)\end{array}$ & NA & NA & $\begin{array}{l}\text { - Higher composite } \\
\text { comorbidity } \\
\text { score }{ }^{\star}(\mathrm{OR}=1.52, \\
95 \% \mathrm{Cl}: 1.02-2.33) \\
\text { - ICU admission } \\
\text { (OR }=4.83,95 \% \mathrm{Cl} \text { : } \\
1.46-17.15)\end{array}$ & NA & NA & $\begin{array}{l}\text { Elevated D- } \\
\text { dimer, lactate, } \\
\text { and LDH }\end{array}$ & NA & NA \\
\hline Luo et al..$^{[16]}$ & $\begin{array}{l}\text { Lung cancer }(N= \\
101)\end{array}$ & $\begin{array}{l}\text { Advancing age } \\
(\mathrm{OR}=2.01 \\
95 \% \mathrm{Cl}: 1.34- \\
3.19)\end{array}$ & NA & $\begin{array}{l}\text { OR 2.9, } \\
95 \% \mathrm{Cl}: \\
1.07-9.44)\end{array}$ & $\begin{array}{l}- \text { COPD (OR = } \\
3.87,95 \% \mathrm{Cl}: 1.35- \\
9.68) \\
- \text { HTN (OR }=2.68 \\
95 \% \text { Cl: } 1.14-6.14)\end{array}$ & NA & NA & NA & NA & NA \\
\hline Lee et al. ${ }^{[8]}$ & $\begin{array}{l}\text { All cancers }(N= \\
800)\end{array}$ & $\begin{array}{l}\text { OR }=9.42 \\
95 \% \mathrm{Cl}: 6.56- \\
10.02, P< \\
0.0001\end{array}$ & $\begin{array}{l}\mathrm{OR}=1.67 \\
(1.19- \\
2.34), P= \\
0.003)\end{array}$ & NA & $\begin{array}{l}-\mathrm{HTN}(\mathrm{OR}=1.95 \\
1.36-2.80, P< \\
0.001) \\
-\mathrm{CVD}(\mathrm{OR}=2.32 \\
1.47-3.64)\end{array}$ & NA & NA & NA & NA & NA \\
\hline Kuderer et al..$^{[7]}$ & $\begin{array}{l}\text { All cancers }(N= \\
928)\end{array}$ & $\begin{array}{l}\text { Increased age } \\
(\mathrm{OR}=1.84 \\
95 \% \mathrm{Cl}: 1.53- \\
2.21)\end{array}$ & $\begin{array}{l}\text { OR }=1.63 \\
95 \% \mathrm{Cl} \\
1.07-2.48\end{array}$ & $\begin{array}{l}\text { OR }=1.60 \\
95 \% \mathrm{Cl} \\
1.03-2.47\end{array}$ & $\begin{array}{l}\text { Number of } \\
\text { comorbidities (two } \\
\text { vs. none: OR = } \\
4.50,95 \% \mathrm{Cl}: 1.33- \\
15.28)\end{array}$ & $\begin{array}{l}\text { ECOG } 2 \text { or } \\
\text { more (OR = } \\
3.89 \\
95 \% \mathrm{Cl} 2.11- \\
7.18)\end{array}$ & $\begin{array}{l}\text { Active cancer } \\
\text { (progressing vs. } \\
\text { remission: OR = } \\
5.20,95 \% \text { Cl: } 2.77- \\
9.77 \text { ) }\end{array}$ & & $\begin{array}{l}\text { Azithromycin + } \\
\text { hydroxychloroquine (vs. } \\
\text { treatment with neither: OR } \\
=2.93,95 \% \text { Cl: } 1.79-4.79 \text { ) }\end{array}$ & \\
\hline Garassino et al. ${ }^{[11,20]}$ & $\begin{array}{l}\text { Lung cancer }(N= \\
400)\end{array}$ & $\begin{array}{l}\text { Age }>65(\mathrm{OR} \\
=1.70,95 \% \mathrm{Cl}: \\
1.09-2.63, P= \\
0.018)\end{array}$ & NA & NA & NA & $\begin{array}{l}\text { ECOG } \geq 1 \\
(\mathrm{OR}=2.14 \\
95 \% \mathrm{Cl}: 1.11- \\
4.11, P< \\
0.001)\end{array}$ & NA & NA & NA & $\begin{array}{l}\text { Use of steroids } \\
\text { (equivalent of prednisone } \\
>10 \mathrm{mg} / \text { day) (OR = } \\
1.49,95 \% \mathrm{Cl}: 1.00-2.23, P \\
=0.052 \text { ) } \\
\text { Chemotherapy (+ or - } \\
\text { immunotherapy) (OR = } \\
1.71,95 \% \mathrm{Cl}: 1.12-2.63, P \\
=0.025)\end{array}$ \\
\hline
\end{tabular}

\#- Only positive associations reported. *Within 4 weeks before symptom onset; ${ }^{* *}$ Composite score defined as the sum of indicators for diabetes mellitus (DM), hypertension, chronic lung disease, chronic kidney disease, coronary artery disease, and congestive heart failure capped at a maximum of 3. NA: Not applicable; OR: odds ratio; Cl: confidence interval; ICU: intensive care unit; LDH: lactate dehydrogenase; COPD: chronic obstructive pulmonary disease; HTN: hypertension; ECOG: Eastern Cooperative Oncology Group. 


\section{DECLARATIONS}

\section{Authors' contributions}

Concept proposal: Kulkarni AA, Wilson G, Fujioka N, Patel MR

Extracting data and literature review: Kulkarni AA, Wilson G, Fujioka N, Patel MR

Manuscript writing and editing: Kulkarni AA, Wilson G, Fujioka N, Patel MR

\section{Availability of data and materials}

Not applicable.

\section{Financial support and sponsorship}

Kulkarni AA - University of Minnesota COVID-19 Rapid Response grant.

\section{Conflicts of interest}

The authors declared that there are no conflicts of interest.

\section{Ethical approval and consent to participate}

Not applicable.

\section{Consent for publication}

Not applicable.

\section{Copyright}

(c) The Author(s) 2021.

\section{REFERENCES}

1. Siegel RL, Miller KD, Jemal A. Cancer statistics, 2020. CA Cancer J Clin 2020;70:7-30. DOI PubMed

2. CDC COVID data tracker. Available from: https://covid.cdc.gov/covid-data-tracker/\#county-view [Last accessed on 26 May 2021]. DOI PubMed PMC

3. Williamson EJ, Walker AJ, Bhaskaran K, et al. Factors associated with COVID-19-related death using OpenSAFELY. Nature 2020;584:430-6. DOI PubMed

4. Docherty AB, Harrison EM, Green CA, et al; ISARIC4C investigators. Features of 20133 UK patients in hospital with covid-19 using the ISARIC WHO Clinical Characterisation Protocol: prospective observational cohort study. BMJ 2020;369:m1985. DOI PubMed PMC

5. Malik P, Patel U, Mehta D, et al. Biomarkers and outcomes of COVID-19 hospitalisations: systematic review and meta-analysis. BMJ Evid Based Med 2021;26:107-8. DOI PubMed PMC

6. Ruan Q, Yang K, Wang W, Jiang L, Song J. Clinical predictors of mortality due to COVID-19 based on an analysis of data of 150 patients from Wuhan, China. Intensive Care Med 2020;46:846-8. DOI PubMed PMC

7. Kuderer NM, Choueiri TK, Shah DP, et al. Clinical impact of COVID-19 on patients with cancer (CCC19): a cohort study. Lancet 2020;395:1907-18. DOI PubMed PMC

8. Lee LY, Cazier J, Angelis V, et al. COVID-19 mortality in patients with cancer on chemotherapy or other anticancer treatments: a prospective cohort study. Lancet 2020;395:1919-26. DOI PubMed PMC

9. Dai M, Liu D, Liu M, et al. Patients with cancer appear more vulnerable to SARS-CoV-2: A multicenter study during the COVID-19 outbreak. Cancer Discov 2020;10:783-91. DOI PubMed PMC

10. Mehta V, Goel S, Kabarriti R, et al. Case fatality rate of cancer patients with COVID-19 in a New York hospital system. Cancer Discov 2020;10:935-41. DOI PubMed PMC

11. Garassino MC, Whisenant JG, Huang L, et al. COVID-19 in patients with thoracic malignancies (TERAVOLT): first results of an international, registry-based, cohort study. Lancet Oncol 2020;21:914-22. DOI PubMed PMC

12. Guan WJ, Ni ZY, Hu Y, et al; China Medical Treatment Expert Group for Covid-19. Clinical characteristics of coronavirus disease 2019 in China. N Engl J Med 2020;382:1708-20. DOI PubMed PMC

13. Yang K, Sheng Y, Huang C, et al. Clinical characteristics, outcomes, and risk factors for mortality in patients with cancer and COVID19 in Hubei, China: a multicentre, retrospective, cohort study. Lancet Oncol 2020;21:904-13. DOI PubMed PMC

14. Yarza R, Bover M, Paredes D, et al. SARS-CoV-2 infection in cancer patients undergoing active treatment: analysis of clinical features and predictive factors for severe respiratory failure and death. Eur J Cancer 2020;135:242-50. DOI PubMed PMC

15. Assaad S, Avrillon V, Fournier ML, et al. High mortality rate in cancer patients with symptoms of COVID-19 with or without detectable SARS-COV-2 on RT-PCR. Eur J Cancer 2020;135:251-9. DOI PubMed PMC 
16. Luo J, Rizvi H, Preeshagul IR, et al. COVID-19 in patients with lung cancer. Ann Oncol 2020;31:1386-96. DOI PubMed PMC

17. Liang W, Guan W, Chen R, et al. Cancer patients in SARS-CoV-2 infection: a nationwide analysis in China. Lancet Oncol 2020;21:335-7. DOI PubMed PMC

18. Luo J, Rizvi H, Egger JV, Preeshagul IR, Wolchok JD, Hellmann MD. Impact of PD-1 blockade on severity of COVID-19 in patients with lung cancers. Cancer Discov 2020;10:1121-8. DOI PubMed PMC

19. AACR COVID-19 and Cancer Virtual Meeting: The distressing intersection of the pandemic and noncommunicable diseases American Association for Cancer Research (AACR). Available from: https://www.aacr.org/professionals/blog/aacr-covid-19-andcancer-virtual-meeting-the-distressing-intersection-of-the-pandemic-and-noncommunicable-diseases/ [Last accessed on 26 May 2021 ].

20. Horn L, Whisenant JG, Torri V, et al. Thoracic Cancers International COVID-19 Collaboration (TERAVOLT): impact of type of cancer therapy and COVID therapy on survival. J Clin Oncol 2020;38:LBA111. DOI

21. AACR virtual meeting: COVID-19 and cancer. Available from: https://www.aacr.org/meeting/aacr-virtual-meeting-covid-19-andcancer/program/ [Last accessed on 26 May 2021].

22. International Association for the Study of Lung Cancer. Available from: https://library.iaslc.org/conferenceprogram?product_id $=20 \&$ author $=\&$ category $=\&$ date $=\&$ session_type $=\&$ session $=\&$ presentation $=\&$ keyword $=$ umit $[$ Last accessed on 26 May 2021].

23. Desai A, Gupta R, Advani S, et al. Mortality in hospitalized patients with cancer and coronavirus disease 2019: a systematic review and meta-analysis of cohort studies. Cancer 2021;127:1459-68. DOI PubMed

24. Zhang H, Han H, He T, et al. Clinical characteristics and outcomes of COVID-19-infected cancer patients: a systematic review and meta-analysis. J Natl Cancer Inst 2021;113:371-80. DOI PubMed PMC

25. Yekedüz E, Utkan G, Ürün Y. A systematic review and meta-analysis: the effect of active cancer treatment on severity of COVID-19. Eur J Cancer 2020;141:92-104. DOI PubMed PMC

26. ASCO COVID-19 guidelines. Available from: https://www.asco.org/sites/new-www.asco.org/files/content-files/2020-ASCO-GuideCancer-COVID19.pdf [Last accessed on 26 May 2021].

27. Cancer Patient Management During the COVID-19 Pandemic. Available from: https://www.esmo.org/guidelines/cancer-patientmanagement-during-the-covid-19-pandemic [Last accessed on 26 May 2021].

28. Coronavirus disease 2019 (COVID-19) resources for the Cancer Care Community. Available from: https://www.nccn.org/covid-19/ [Last accessed on 26 May 2021]. 